\title{
PRACTICAL STABILITY OF NONLINEAR TIME-VARYING IMPULSIVE CASCADE SYSTEMS
}

\author{
FATIMA TOUMI, ABDELGHANI OUAHAB, and ABDERRHMANE OUMANSOUR
}

\begin{abstract}
In this article practical stability of impulsive time-varying cascade systems is investigated. In this way, we extend some existing results under more generalized assumptions. Examples are given to show the feasibility of our results.
\end{abstract}

MSC 2010. 34K20, 93D05, 34K38.

Key words. Cascade systems, Lyapunov theory, practical stability, impulsive equation.

\section{REFERENCES}

[1] J.P. Aubin, Impulse Differential Inclusions and Hybrid Systems: a Viability Approach, Lecture Notes, Université Paris-Dauphine, 2002.

[2] D.D. Bainov, V. Lakshmikantham and P.S. Simeonov, Theory of Impulsive Differential Equations, World Scientific, Singapore, 1989.

[3] A. Benabdallah, I. Ellouze and M. Hammami, Pratical stability of nonlinear timevarying cascade systems. J. Dyn. Control Syst., 15 (2009), 45-62.

[4] D. Beldjerd, L. Oudjedi and M. Remili, Practical exponential stability of nonlinear timevarying cascade systems. Rev. Roumaine Math. Pures Appl., 60 (2015), 1-16.

[5] A. Chaillet and A. Loria, Necessary and sufficient conditions for uniform semiglobal pratical asymptotic: Application to cascade systems, Automatica 42 (2006), 1899-1906.

[6] M. Corless, Guaranteed rates of exponential convergence of uncertain systems, J. Optim. Theory Appl., 64 (1990), 481-494.

[7] J.R. Graef, J. Henderson and A. Ouahab, Impulsive Differential Inclusions: A Fixed Point Approach, De Gruyter Series in Nonlinear Analysis and Applications, 20, de Gruyter, Berlin, 2013.

[8] W. M. Haddad and V. Chellaboina, Nonlinear Dynamical Systems and Control, Princeton University Press, Princeton, 2008.

[9] J.K. Hale, Ordinary Differential Equations, Krieger Publishing Company Malabar, Florida, 1980.

[10] M. Jankovic, R. Sepulchre and P.V. Kokotovic, Constructive Lyapunov stabilisation of nonlinear cascade systems, IEEE Trans. Automat. Control, 41 (1996), 1723-1736.

[11] H.K. Khalil, Nonlinear Systems, Prentice-Hall, New York, 2002.

[12] V. Lakshmikantham, S. Leela and A.A. Martyuk, Practical Stability of Nonlinear Systems, World Scientific, 1990.

The research of authors has been partially supported by the General Direction of Scientific Research and Technological Development (DGRSDT), Algeria.

DOI: 10.24193/mathcluj.2021.1.12 
[13] N.M. Linh and V.N. Phat, Exponential stability of nonlinear time-varying differential equations and applications, Electron. J. Differential Equations, 2001, 34 (2001), 1-13.

[14] H.J. Marquez, Nonlinear Control Systems Analysis and Design. Wiley Interscience, 2003.

[15] E. Panteley and A. Loria, On global uniform asymptotic stability of nonlinear timevarying systems in cascade, Systems Control Lett., 33 (1998), 131-138.

[16] E. Panteley and A. Loria, Growth rate conditions for uniform asymptotic stability of cascade time-varying systems. Automatica, 37 (2001), 453-460.

[17] A. Saberi, P.V. Kokotovic and H.J. Sussman, Global stabilization of partially linear composed systems, SIAM J. Control Optim., 28 (1990), 1491-1503.

[18] A.M. Samoilenko and N.A. Perestyuk, Impulsive Differential Equations, World Scientific, Singapore, 1995.

[19] P. Seibert and R. Suarez, Global stabilization of nonlinear cascade systems, Systems Control Lett., 14 (1990), 347-352.

[20] Y.J. Sun, C.H. Lien and J.G. Hsieh, Global exponential stabilisation for a class of uncertain nonlinear systems with control constraints, IEEE Trans. Automat. Control, 43 (1998), 674-677.

[21] H.J. Sussmann and P.V. Kokotović, The peaking phenomenon and the global stabilization of nonlinear systems, IEEE Trans. Automat. Control, 36 (1991), 424-439.

Received July 30, 2019

Accepted November 24, 2020
Sidi-Bel-Abbès University

Laboratory of Mathematics

PO Box 89, 22000 Sidi-Bel-Abbès, Algeria

E-mail: fatimatou84@yahoo.fr

E-mail: agh_ouahab@yahoo.fr

E-mail: a_oumansour@yahoo.fr 